\title{
Relation of ECHO Doppler uterin in the first trimester to fetal SGA or IUGR
}

\author{
Bashkim ISMAILI \\ IPH Special Hospital for Obstetry-Gyneacology “Mother Teresa”, Chair-Skopje, Republic of North \\ Macedonia
}

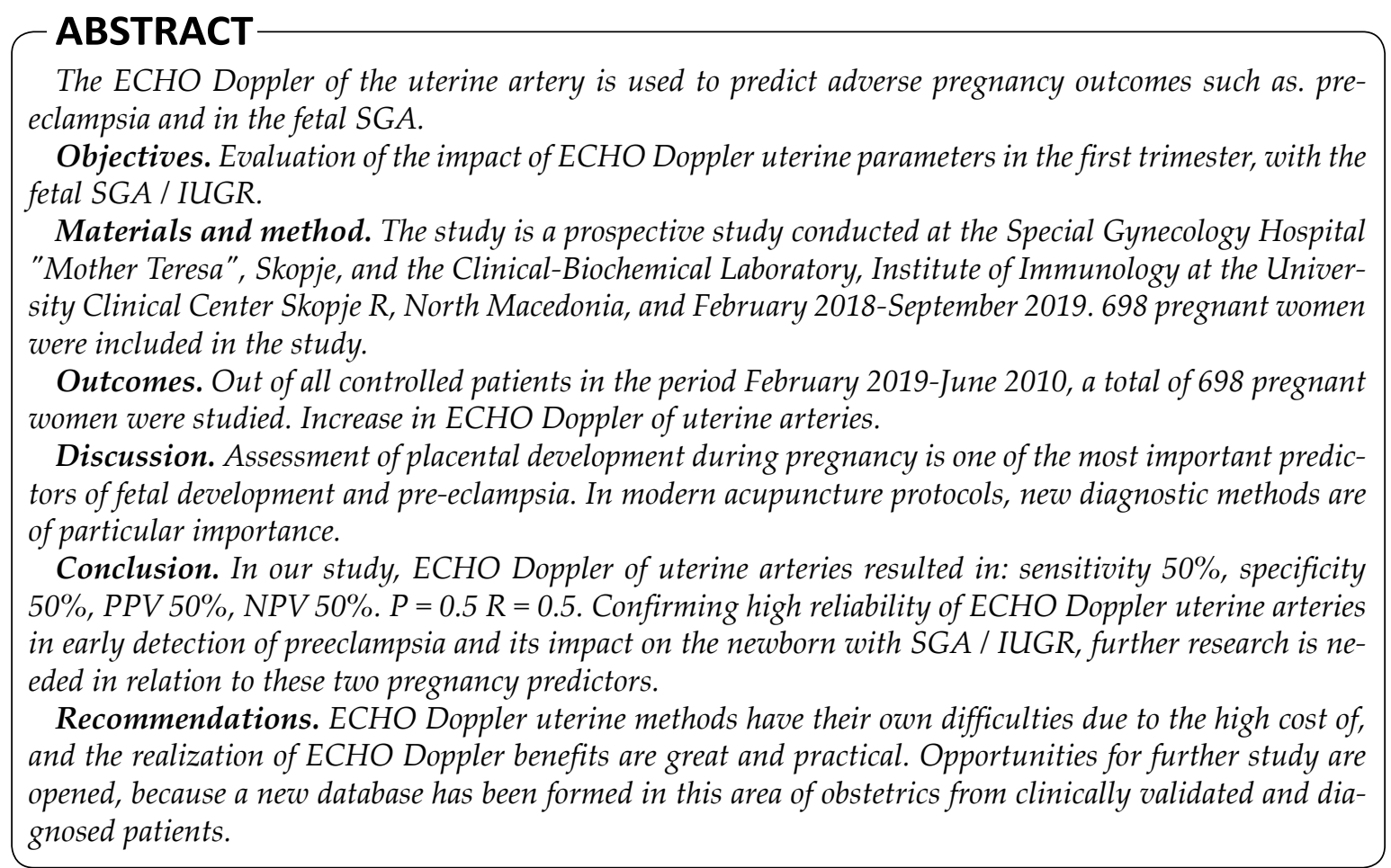

Keywords: uterine ECHO Doppler, SGA

\section{INTRODUCTION}

Diagnosis of pregnancy and fetal condition is achieved through several contemporary clinical, biochemical, physical and electronic methods for establishing a fetoplacental fetal diagnosis.

These processes result in typical physiological changes that can be observed in the mother, placenta, and fetus. Trophoblastic implantation and fertilization of the placenta plays a crucial role in its development as an organ for the transport of food and oxygen to the fetus $(1,2)$.

As placental dysfunction occurs in the first trimester of adherence, the last decade provides the opportunity to placental markers early detection of patients at risk for acupuncture clinical disease and their association with prediction of fruit growth (3). New protocols have been introduced. Diagnostic and predictive clinical application sic. It is a Doppler ultrasound method of the uterine ar- 
teries, which is very predictive of the occurrence of eclampsia in the pregnancy which then has a direct impact on fetal growth. Roughly 1 in 10 babies are SGA / IUGR, the incidence of SGA / IUGR is higher in people of color than in white people. In developing countries in $1 / 3$ of the cases the native causes are $\mathrm{JH}$-gestation, while in $25 \%$ of fetal causes of increased in utero stagnation is hunger (4). LBW has an incidence of 8-10\% in developed countries and $63 \%$ in developing countries. Pre-eclampsia complicates $4-8 \%$ of pregnancies (5). The average weight of the newborn is 2,500 to 4,000 gr with a length of $51 \mathrm{~cm}$. The term low birth weight (LBW) refers to weight $<2,500$ grams regardless of the age of the pregnancy.Most babies weighing $<2,500 \mathrm{~g}$ give birth prematurely (are born before week 37 of pregnancy). In contrast, the terms intrauterine growth restriction (IUGR) and small for fetal gestational age (SGA) are calculated with reference to the age of pregnancy (6). SGAs are fetuses who have birth weight less than $10 \%$ for their gestational age (7). IUGR is a term used for fetuses who fail to make their intrauterine growth optimal. These children are pathologically young, consequently those children have an increased risk for neurological problems, congenital malformations, hypoglycemia, hypocalcaemia, and respiratory distress syndromes $(8,9)$. Synonymous for fruit malnutrition, chronic fetal distress, newborn with body mass in relation to SGA gestational age, increased intrauterine stagnation, (intrauterine growth retardation-IUGR (10) (figure 1).

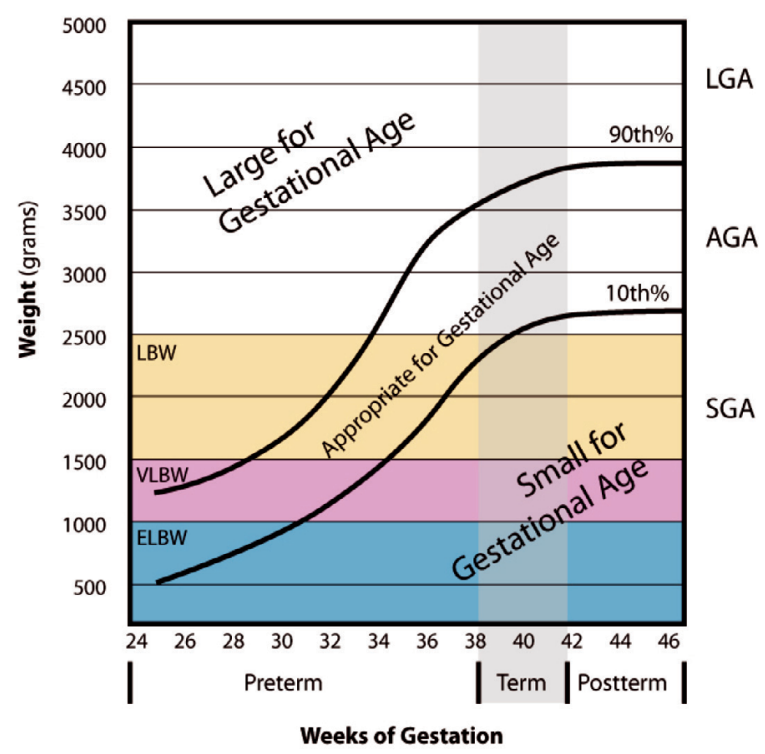

FIGURE 1. Clasification of newborn with weeks and weight

Although some babies are constitutively small due to genetics (their parents are small), most SGA babies are small due to the growth problems that occur during pregnancy (11). If the baby's birth weight is below the 10th percentile for pregnancy, the baby is also SGA. It is important to note that not all SGA newborns are IUGR, they are simply younger than normal because their parents are younger $(12,13)$.

Low birth weight (LBW), a newborn with low birth weight, is defined as a newborn weighing less than 2,500 grams irrespective of gestational age (14).

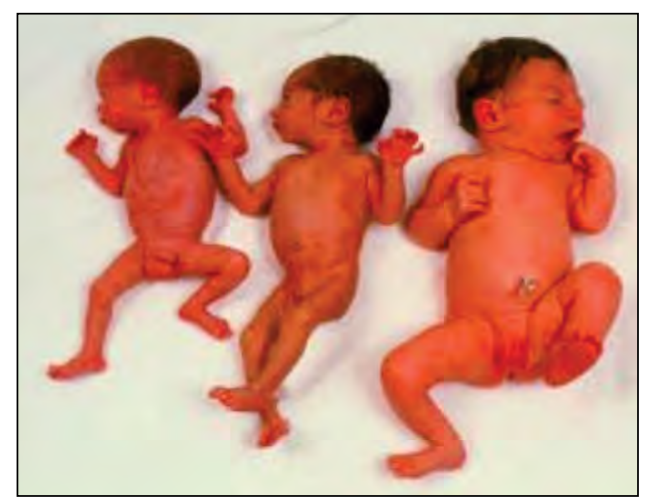

FIGURE 2. Presentation of newborn SGA in relation to normal eutrophic newborn

Accurate screening protocols exist throughout the world in the first trimester, but objective factors sometimes influence non-adherence to these protocols, such as non-screening of pregnancies, non-management of pregnancies by primary care physicians, and so on (15). As mentioned above, preeclampsia and increased fetal stagnation are linked (16). EPH-Gestosis occurs in approximately $10-15 \%$ of first pregnancies and $5-10 \%$ of later pregnancies. Cases are diagnosed after the 34 th week of pregnancy (Robson, 1999).

ECHO Doppler of uterine arteries, In daily practice protocols there are a number of methods used in the form of screening for early diagnosis and prediction of concomitant concomitant and intrauterine growth of the fetus, undoubtedly the method used by the last uterine artery right and left, methods that are very important for detecting pregnancies that have early signs of developing JIT gestosis.

Increasingly, research is focused on early identification of pregnancy risks and intrauterine fetal development, thus creating early management strategies to minimize pregnancy risks. In the first trimester, and its role in predicting subsequent complications of pregnancy is discussed (17). ECHO uterine artery Doppler is used to predict adverse pregnancy outcomes such as "pre-eclampsia" and fetal "SGA" (small fetus for gestational age) (figure 3). 


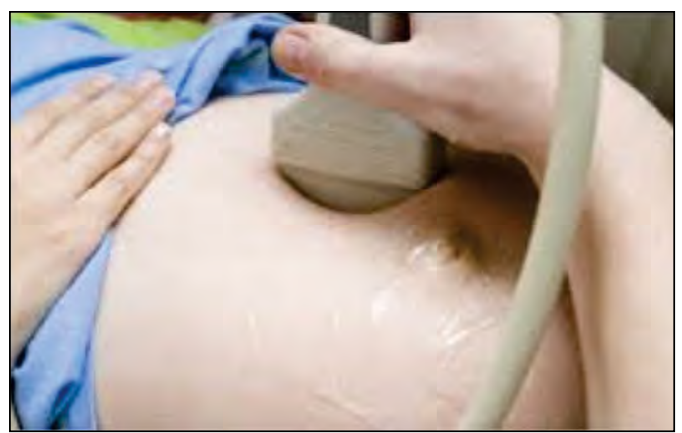

FIGURE 3. ECHO uterine artery Doppler

Uterine Doppler Ultrasound Examination (UtA) has become a valuable method for indirect assessment of uterine circulation, from the beginning of gestation, and has been considered as a potential screening tool for the development of preeclampsia, fetal growth restriction, defect of placenta, and death $(18,19,20)$. Abnormal findings of UtA Doppler in patients with pregnancy-induced hypertension and / or small mephetus (SGA) from 12-16 weeks, are directly related to adverse outcomes. Maternal and / or perinatal (21). Pulsivity Index $(\mathrm{PI})$ is currently the most used index for the UtA Doppler evaluation.

\section{OBJECTIVES}

Impact Assessment of ECHO Doppler uterine parameters in the First trimester, with SGA / IUGR fetus.

\section{MATERIAL AND METHOD}

The study is a prospective study conducted at the Special Mother-Gynecology Hospital "Mother Teresa", Skopje-Skopje, and the Clinical-Biochemical Laboratory, Institute of Immunology at the University Clinical Center Skopje R, North Macedonia, February 2019 The study included 698 pregnant, aged $17-41$ years, mean age 28.73 years \pm 3.5 months, between $11+0$ and $15+1$ week of gestation. The EHO Doppler PI of the uterine arteries was counted as positive or lower than> 1.8 and negative with normal range <1.9.SGA / IUGR was calculated as $<2,500 \mathrm{~g}$ regardless of age of pregnancy.

\section{STATISTICAL CALCULATION OF VALUE}

The collected data were recorded in Microsoft Access database, calculated using separate forms of Microsoft Exel 2007 and Windows 7. Computer data processing was performed with STATISTICA for Windows 8.0 and SPSS 8.0 for MS Windows.
Test Fischer was used for group comparison (22, $23)$, the MANN-Whitney test was used to compare variables (24).

\section{OUTCOMES}

Out of all controlled patients in the period February 2018-February 2019, a total of 698 pregnancies were studied, mean age 28.73 years \pm 3.5 months, minimum age of study was 17 years, maximum 42 years. Of all 698 studies, 284 cases resulted in ECHO Doppler PI of the uterine arteries resulting in increased resistance in both uterine arteries, and in 414 cases PI resulted in normal resistance. Results obtained from data with ECHO Doppler of uterine arteries right and left in patients who resulted in SGA / IUGR resulted in 2 or (50\%) two cases of increased resistance and in 2 or $(50 \%)$ cases no increase in resistance.

\section{TABELAR AND GRAPHICAL REPRESENTATION OF DATA BY RESULTS}

TABLE 1. Table representation of all 698 SGA / IUGR-born

\begin{tabular}{|l|c|c|}
\hline Born SGAI/UGR & In Total 698 & $100 \%$ \\
\hline SGA/IUGR & 4 & $0.57 \%$ \\
\hline EUTROPHIC & 694 & $99.43 \%$ \\
\hline
\end{tabular}

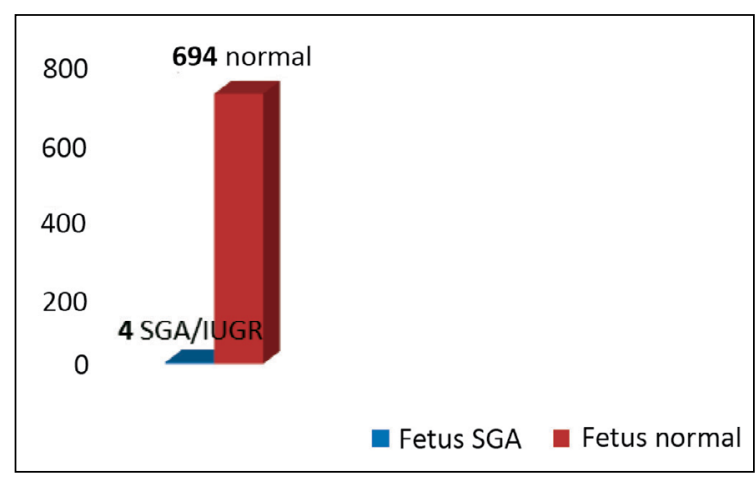

FIGURE 4. Graphical representation of all 698 SGA / IUGR-born

TABLE 2. Tabelar presentation of 4 cases have resulted $S G A / I U G R$

\begin{tabular}{|l|c|c|}
\hline $\begin{array}{l}\text { Fetus in total } \\
\text { SGA/IUGR }\end{array}$ & 4 & $100 \%$ \\
\hline $\begin{array}{l}\text { Normal values of PI- ECHO } \\
\text { uterin Doppler }\end{array}$ & 2 & $50 \%$ \\
\hline $\begin{array}{l}\text { Pathological values of PI-ECHO } \\
\text { uterin Doppler }\end{array}$ & 2 & $50 \%$ \\
\hline
\end{tabular}

Presentation of statistical calculated of sensitivity, sensitivity, PPV, NPV to ECHO Doppler uter- 


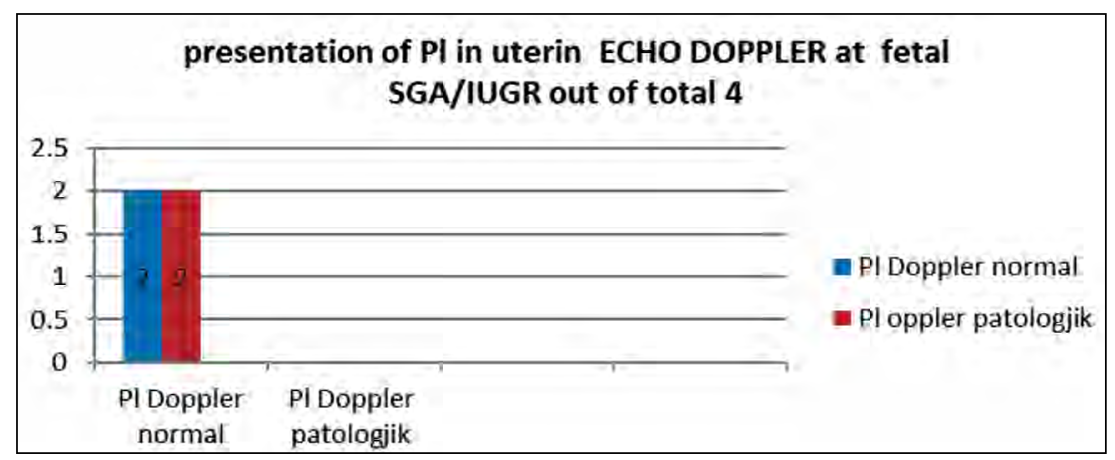

FIGURE 5. Graphical presentation of 4 cases have resulted SGA/IUGR

ine. Sensitivity $50 \%$, specificity $50 \%$, PPV 50\%, NPV $50 \%, P=0.5 R=0.5$.

\section{DISCUSSION}

Assessment of placental development during pregnancy is one of the most important predictors of fetal development and pre-eclampsia. In modern acupuncture protocols, new diagnostic methods are of particular importance. Utilizing these methods is often impossible, since their cost is high, a maximum coordination of primary and secondary level obstetricians is also required to increase diagnostic efficiency.ECHO Doppler uterin: sensitivity $50 \%$, specificity $50 \%$, PPV $50 \%$, NPV $50 \%, P=0.52, R=0.5$. Confirming high predictive values of ECHO Doppler uterin, but nonetheless that these parameters should be combined with other pregnancy diagnostic factors, and further research is needed on these two predictors of pregnancy. Fetus SGA / IUGR in 4 or $0.57 \%$. Early diag- nostic data may reduce inadequate sub-hospital controls, proper and adequate monitoring of these pregnancies, reduce the length of stay or exclude the need for hospitalization.

\section{CONCLUSIONS}

ECHO Doppler of uterine arteries resulted in: $50 \%$ sensitivity, specificity 50\%, PPV 50\%, NPV $50 \% . P=0.5 R=0.5$.

\section{RECOMMENDATIONS}

ECHO Doppler uterine methods have their own difficulties due to the high cost of, and the realization of ECHO Doppler benefits are great and practical. Opportunities for further study are opened, because a new database has been formed in this area of obstetrics from clinically validated and diagnosed patients.

Conflict of interest: none declared Financial support: none declared

\section{REFERENCES}

1. Hernandez, Andrade E, Brodszki J, Lingman G, Gudmundsson S, Molin J, Marsál K. Uterine artery score and perinatal outcome. Ultrasound Obstet Gynecol 2002; 19: 438- 442.

2. Vergani $P$, Roncaglia N, Andreotti $C$, Arreghini A, Teruzzi M, Pezzullo JC, Ghidini A. Prognostic value of uterine artery Doppler velocimetry in growth restricted fetuses delivered near term. Am J Obstet Gynecol 2002; 187: 932- 936.

3. Kingdom J, Huppertz B, Seaward G, Kaufmann P. Development of the placental villous tree and its consequences for fetal growth. Eur J Obstet Gynecol Reprod Biol 2000; 92: 35-43.

4. Lawn JE, CousensS, Zupan J. 4 million neonatal deaths: when? Where? Why? The Lancet 2005. 365 (9462): 891-900.
5. Steegers EA, von Dadelszen P, Duvekot JJ, Pijnenborg R. Pre-eclampsia. Lancet. 2010;376(9741):631-44.

6. Kone E, Çeka Xh, Dedja E. TW Sadler. Embriologjia mjekësore e Langman, 2013. 10. Chamberlain G, Phillip E, Howlett BC, Masters K 1978 British births 1970. Vol 2. Obstetric Care. London: William Heinemann Medical.

7. Tidwell SC, Ho HN, Chiu WH, Torry RJ, Low maternal serum levels of placenta growth factor as an antecedent of clinical preeclampsia. AmJObstet Gynecol 2001;184:1267-1272.

8. Vvan den Elzen HJ, Cohen-Overbeek TE, Grobbee DE, Quartero RW, Wladimiroff JW. Early uterine artery Doppler velocimetry and the outcome of pregnancy in women aged 35 years and older. Ultrasound Obstet Gynecol 1995; 5: 328-333.

9. Kone E, Çeka Xh, Dedja E. T.W.Sadler Embriologjia mjekësore e Langman, 2013. 10. Chamberlain G, Phillip E, Howlett BC, Masters K 1978 British Births 1970. Vol 2. Obstetric Care. London: William Heinemann Medical.

10. Small for gestational age (SGA) at MedlinePlus. Update Date: 8/4/2009. Updated by: Linda J. Vorvick. Also reviewed by David Zieve.

11. S. Muthayya. Maternal nutrition \& low birth weight - what is really important? Indian Journal of Medical Research 2009, vol. 130, no. 5, pp. 600-608.

12. Small for gestational age (SGA) at MedlinePlus. Update Date: 8/4/2009. 
Updated by: Linda J. Vorvick. Also reviewed by David Zieve.

13. Vikram S Dogra. Intrauterine Growth Retardation. Retrieved 2007.11-28.

14. Michael G Ross. Fetal Growth Restriction. Retrieved 201002-25.

15. Mello $\mathrm{G}$ et al. Risk factors for fetal macrosomia: The importance of a positive oral glucose challenge test. European Journal of Endocrinology. 1997; 137 :27-33.

16. Kurdi W, Campbell S, Aquilina J, England P, Harrington K. The role of color Doppler imaging of the uterine arteries at 20 weeks' gestation in stratifying antenatal care. Ultrasound Obstet Gynecol 1998; 12: 339-345.

17. Jurkovic D, Jauniaux E, Kurjak A, Hustin J, Campbell S, Nicolaides KH. Transvaginal color Doppler assessment of the uteroplacental circulation in early pregnancy. Obstet Gynecol 1991;365-369.
18. R Cantwell, T Clutton-Brock, G Cooper et al. Saving Mothers' Lives: Reviewing maternal deaths to make motherhood safer: 2006-2008. The Eighth Report of the Confidential Enquiries into Maternal Deaths in theThe eighth report of the confidential enquiries into maternal deaths in the United Kingdom. BJOG, vol. 118, supplement 1, pp. 1-203, 2011.

19. SC Kane, F Da Silva Costa, S Brennecke. First trimester biomarkers in the prediction of later pregnancy complications. BioMed Research International 2014, vol. 2014, Article ID 807196, 6 pages.

20. AE Wallace, GS Whitley, B Thilaganathan, JE Cartwright. Decidual natural killer cell receptor expression is altered in pregnancies with impaired vascular remodeling and a higher risk of preeclampsia. Journal of Leukocyte Biology 2015. vol. 97, no. 1, pp. 79-86.
21. J Lefebvre, S Demers, E Bujold et al. Comparison of two different sites of measurement for transabdominal uterine artery Doppler velocimetry at 11-13 weeks. Ultrasound in Obstetrics and Gynecology 2012, vol. 40, no. 3, pp. 288-292.

22. Fisher RA. On the interpretation of $X 2$ from contingency tables, and the calculation of $P$. Journal of the Royal Statistical Society 1922. 85 (1) 8794

23. Fisher RA. Statistical Methods for Research Workers, 1954. Oliver and Boyd. ISBN 0-05-002170-2.

24. Mann Henry B, Whitney Donald R. On a Test of Whether one of Two Random Variables is Stochastically Larger than the Other. Annals of Mathematical Statistics 1947, 18(1):50-60. 